\title{
Rancang Bangun Modul Praktikum Penggunaan Bipolar Junction Transistor Sebagai Sakelar Berbasis Arduino Mega
}

\author{
Zeka Wijaya Sukma ${ }^{1}$, Sunu Pradana ${ }^{2}$, Abdul Hamid Kurniawan ${ }^{3}$ \\ 1,2,3 Teknik Elektro, Politeknik Negeri Samarinda \\ pradana.sunu@gmail.com
}

\begin{abstract}
Abstrak- BJT (Bipolar Junction Transistor) sebagai sakelar adalah salah satu pokok bahasan pada mata kuliah elektronika daya dan membutuhkan modul praktikum sebagai media dalam proses pembelajarannya. Modul praktikum yang sudah ada relatif kompleks sehingga penulis membuat rancang bangun yang lebih sederhana sehingga mudah untuk diperbaiki saat terjadi kerusakan serta komponen penggantinya mudah untuk ditemukan. BJT dapat berfungsi sebagai sakelar dengan memanfaatkan dua modenya yaitu saturation dan cut off. Pada perancangan modul, penyakelaran dikendalikan oleh Arduino Mega dengan sinyal PWM (Pulse Width Modulation) pada terminal basis, baik BJT NPN maupun BJT PNP. Berdasarkan pengujian saat cut off untuk BJT NPN dan BJT PNP pada beban resistor maupun resistor dengan induktor, nilai tegangan beban $0 \mathrm{~V}$ dan arus beban $0,003 \mathrm{~A}$. sedangkan saat saturation pada beban resistor untuk BJT NPN, nilai tegangan beban 11,45 $\mathrm{V}$ dan arus beban 0,572 A dan BJT PNP, nilai tegangan beban 11,45 $\mathrm{V}$ dan arus beban $0,573 \mathrm{~A}$. pada beban resistor dengan induktor untuk BJT NPN, nilai tegangan beban $11,81 \mathrm{~V}$ dan arus beban 0,122 A dan BJT PNP, nilai tegangan beban 11,79 $\mathrm{V}$ dan arus beban 0,121 A.
\end{abstract}

Kata kunci: BJT, sakelar, elektronika daya, Arduino Mega, PWM, cut off, saturation.

\section{Pendahuluan}

Semakin pesatnya perkembangan teknologi dan ilmu pengetahuan memacu mahasiswa agar aktif berkompetisi dalam mengembangkan diri agar dapat bersaing di dunia industri. Untuk mencapai hal tersebut mahasiswa membutuhkan fasilitas pada pendidikan vokasi berupa kegiatan praktik di laboratorium sebagai penunjang proses pembelajaran.

Proses pembelajaran akan menjadi lebih efektif dengan adanya kegiatan praktikum di dalamnya, karena kegiatan praktikum dapat memfasilitasi pemenuhan capaian mahasiswa. Selain itu, karena adanya pergeseran paradigma metode pembelajaran pada pendidikan vokasi yang lebih berpusat pada mahasiswa atau yang lebih dikenal dengan Student Centered Learning (SCL) dimana mahasiswa berperan aktif dalam mengembangkan pengetahuan dan keterampilan, mengelola pengetahuan dalam mengembangkan karakter mahasiswa, berdiskusi dengan fasilitator atau dosen pengajar, dan bahkan kesalahan dapat menjadi sebuah metode pembelajaran [1], [2].

Pada mata kuliah Elektronika Daya memiliki pokok bahasan yang membahas prinsip pengendalian suatu beban, yaitu penggunaan BJT (Bipolar Junction Transistor) sebagai sakelar. BJT sebagai sakelar dapat mengaktifkan atau menonaktifkan suatu beban dengan hanya menggunakan arus pada sisi input yang kecil.
Pokok bahasan tersebut tentunya akan sulit untuk dipahami tanpa adanya media untuk praktik. Oleh karena itu maka dibutuhkan modul praktikum sebagai media untuk mempelajari elektronika daya agar lebih efektif dan efisien.

Modul praktikum yang sudah ada relatif kompleks yang berakibat sulit untuk diperbaiki dan sulit menemukan komponen penggantinya. Maka dari itu penulis bertujuan untuk membuat rancang bangun yang lebih sederhana dan mudah diperbaiki serta komponen penggantinya mudah untuk ditemukan.

\section{LANDASAN TEORI}

\section{A. BJT (Bipolar Junction Transistor)}

BJT memiliki tiga wilayah atau terminal yang disebut collector (kolektor), emitter (emiter), dan base (basis).

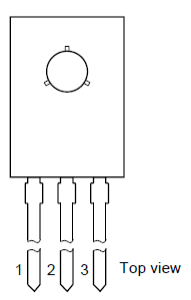

(a)

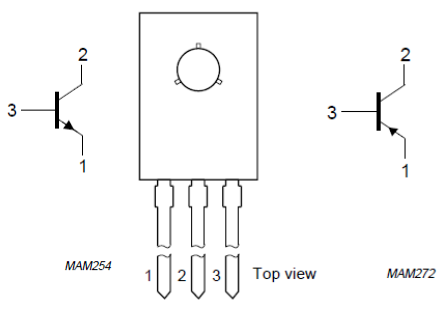

(b)
Gambar 1. Posisi terminal dan simbol BJT, (a) BJT NPN BD139, (b) BJT PNP BD140 [3], [4]

Berdasarkan fungsinya BJT memiliki tiga daerah operasi yang terdiri dari cut off, saturation dan daerah aktif. Daerah operasi BJT dapat dilihat pada Gambar 2.

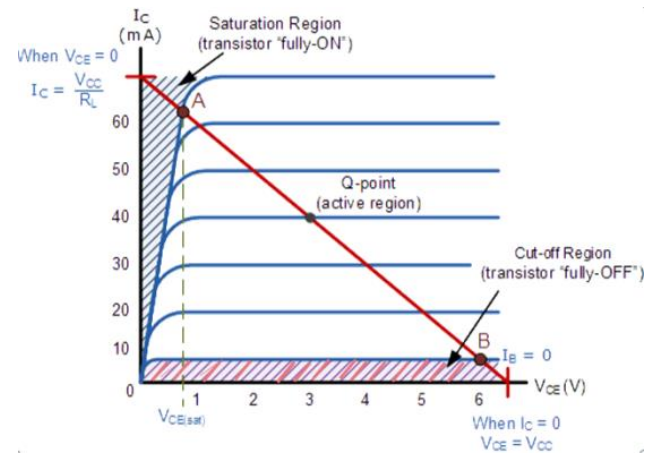

Gambar 2. Daerah operasi BJT [5] 
Daerah operasi BJT terdiri atas:

1. Cut off region yaitu saat base emitter junction dalam keadaan tidak forward biased. Maka, semua arus pada base (basis) dan collector (kolektor) sama dengan nol dan tegangan collector emitter atau $\mathrm{V}_{\mathrm{CE}}$ sama dengan tegangan sumber [6].

2. Saturation (saturasi) yaitu saat base emitter junction dalam keadaan forward biased. Ada cukup arus base yang membuat arus collector dalam keadaan maksimum serta tegangan collector emitter atau $\mathrm{V}_{\mathrm{CE}}$ sangat kecil dibandingkan dengan tegangan sumber [6].

3. Active region (Daerah aktif) yaitu saat BJT berkerja di wilayah aktif atau di antara mode saturation dan cut off, pada wilayah aktif BJT bekerja sebagai amplifier dikarenakan arus base pada BJT dapat mengendalikan arus collector yang lebih besar [6].

BJT dapat berfungsi sebagai sakelar dengan memanfaatkan dua modenya yaitu saturation dan cut off. Saturation (saturasi) adalah saat terminal base dialiri oleh arus, maka transistor seperti sakelar tertutup penuh atau fully on pada saat saturasi (kondisi jenuh), penambahan besar arus basis tidak akan menambah arus kolektor. sedangkan cut off adalah saat terminal base tidak dialiri arus maka transistor seperti sakelar terbuka atau off [7].

Terdapat dua aplikasi dasar dari penyakelaran BJT yang digunakan dalam mengontrol aliran arus yaitu low side switching dan high side switching [8]. Berikut adalah gambar aplikasi dari penyakelaran BJT yang dapat dilihat pada Gambar 3.

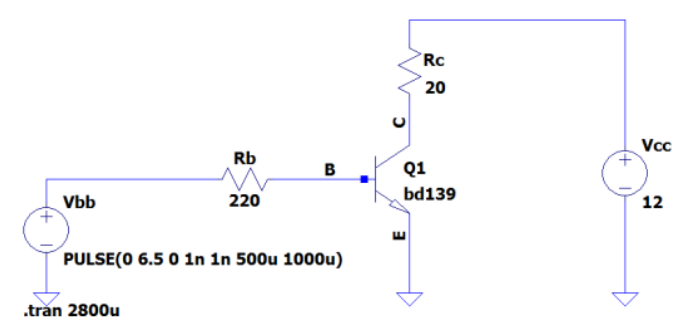

(a)

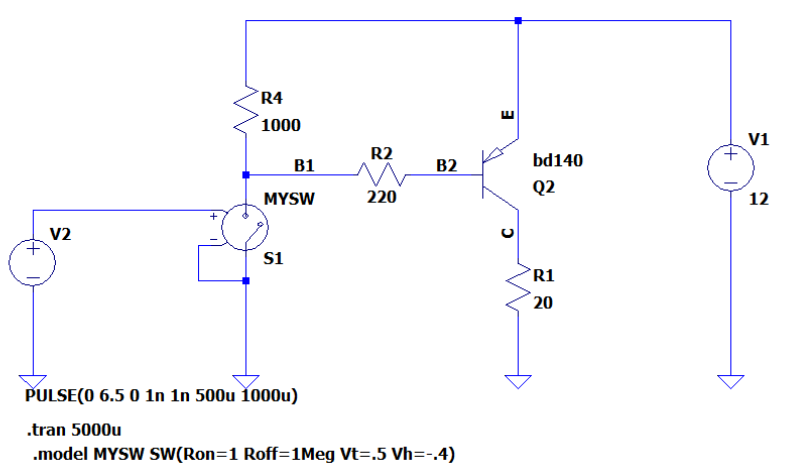

(b)

Gambar 3. Aplikasi penyakelaran BJT, (a) Low side switching, (b) High side swicthing

Submitted: 20/10/2019 Revised: 24/11/2019;

Accepted: 24/11/2019; Online first: 30/06/2020

http://dx.doi.org/10.46964/poligrid.v1i1.343
Gambar. 3 menunjukkan aplikasi penyakelaran BJT, rangkaian disebut sebagai low side switching dikarenakan BJT digunakan sebagai sakelar pada sisi ground sedangkan rangkaian disebut sebagai high switching dikarenakan beban berada pada sisi ground dan untuk BJT PNP memiliki kondisi pengaktifan jika basis dalam keadaan low, oleh karena itu pada basis diberi sakelar untuk menghubungkan dengan ground [8].

\section{B. Arduino Mega 2560}

Arduino adalah suatu perangkat yang terdiri dari perangkat keras dan perangkat lunak yang memungkinkan untuk membuat prototipe suatu rangkaian elektronika yang berbasis mikrokontroler dengan mudah dan cepat [9].

Arduino dapat digunakan dengan mengirimkan instruksi pada papan arduino menggunakan bahasa pemrograman Arduino (bahasa C) pada perangkat lunak Arduino (IDE) [10]. Arduino Mega 2560 dapat dilihat pada Gambar 4.

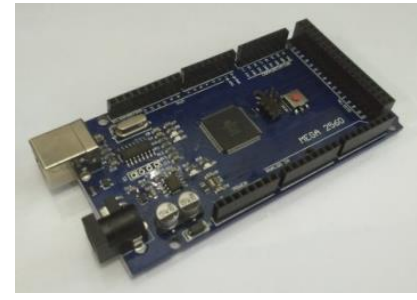

Gambar 4. Arduino Mega 2560

Pengendalian berbasis Arduino Mega menggunakan mikrokontroler ATmega 2560. Arduino Mega memiliki 54 pin input/output digital, yang mana 15 pin dapat digunakan sebagai output PWM (Pulse Width Modulation), 16 input analog, 4 UARTs (hardware serial ports), sebuah $16 \mathrm{MHz}$ crystal oscillator, sebuah koneksi USB, sebuah power jack, dan sebuah ICSP header, dan tombol reset [11].

\section{PWM (Pulse Width Modulation)}

PWM (Pulse Width Modulation) adalah teknik untuk mengatur sinyal digital sedemikian rupa untuk mendapatkan sinyal analog. Pengaturan pada sinyal digital digunakan untuk menghasilkan gelombang berbentuk persegi, yaitu sinyal yang beralih dari kondisi on $(5 \mathrm{~V})$ ke off $(0 \mathrm{~V})$. Perbandingan antara waktu on dengan periode (waktu on ditambah waktu off), disebut duty cycle. Untuk mendapatkan nilai sinyal analog yang bervariasi dapat diatur dengan mengubah nilai duty cycle [12]. Berikut adalah gelombang sinyal PWM yang dapat dilihat pada Gambar 5. 


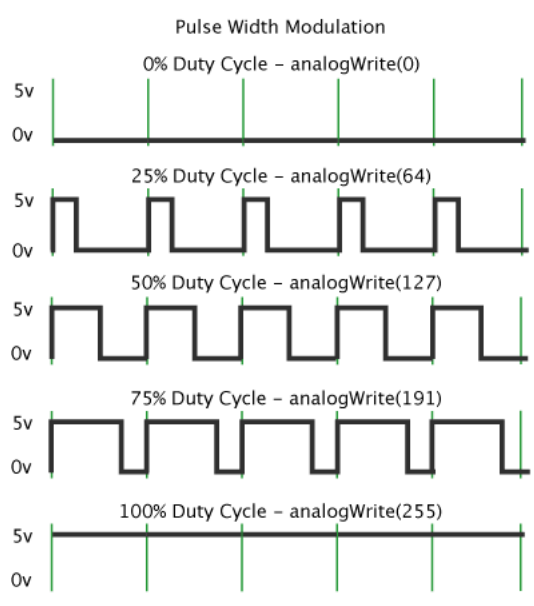

Gambar 5. Gelombang PWM [12]

\section{METOdOLOGI PERANCANGAN}

\section{A. Gambaran Umum Sistem}

Gambaran umum sistem terdiri dari komponen-komponen penyusun modul praktikum. Gambaran umum sistem dibuat agar alur kerja sistem dapat dilihat, sehingga memudahkan dalam perancangan hingga pembuatan modul praktikum. Berikut gambaran umum sistem yang dapat dilihat pada Gambar $\underline{6}$.
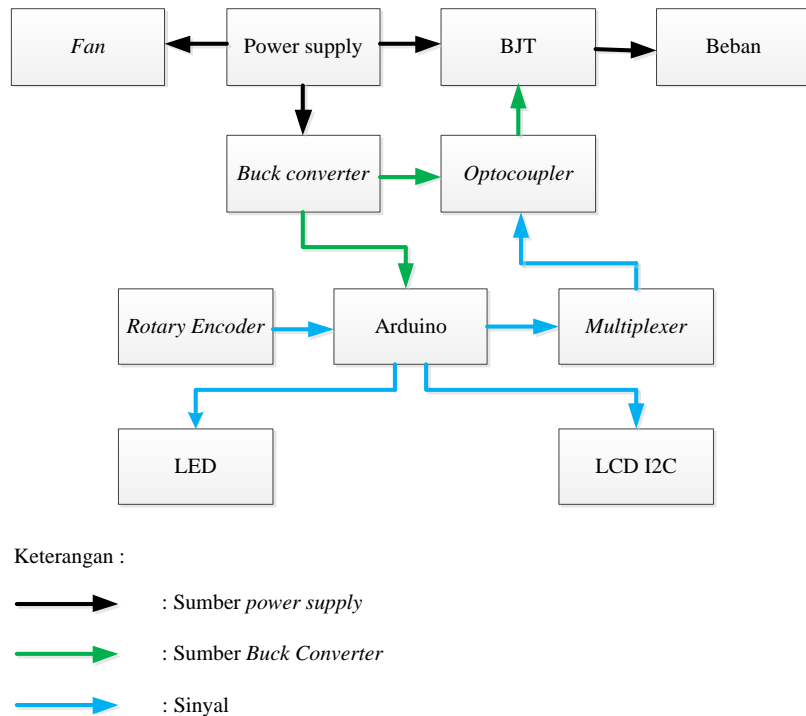

Gambar 6. Gambaran umum sistem

\section{B. Perancangan Sumber Tegangan}

Dalam proses perancangan ditentukan sumber tegangan yang akan digunakan yaitu SMPS (Switch Mode Power Supply) dengan tegangan output $12 \mathrm{~V}$ dan arus 10 A sebagai sumber tegangan fan atau kipas, $\mathrm{V}_{\mathrm{CC}}$ pada modul BJT, dan sebagai input tegangan buck converter XL4005 adjustable 5 A DC-DC step down, input 4-35 V, dan output 1,25-32 V sebagai sumber tegangan untuk Arduino Mega dan basis pada modul BJT.
TABEL 1

PERKIRAAN NILAI ARUS PADA BEBAN

\begin{tabular}{|l|l|}
\hline Beban & Nilai Arus (A) \\
\hline Fan 6x6 (3 buah) & 0,32 \\
\hline Fan 8x8 (2 buah) & 0,40 \\
\hline Penyakelaran BJT & 0,6 \\
\hline Total & 1,32 \\
\hline
\end{tabular}

\section{Perancangan Modul BJT sebagai Sakelar}

Dalam perancangan modul BJT terdapat beberapa proses yang dilakukan seperti perhitungan manual untuk menentukan nilai resistor basis atau $R_{B}$ yang digunakan dengan menggunakan persamaan :

$R_{B}=\left(V_{B B}-V_{B E}\right) / I_{B}$

Setelah melakukan perhitungan maka dapat dilakukan simulasi rangkaian pada aplikasi LTspice untuk mempermudah proses perancangan dan meminimalisir resiko kerusakan.

1). Rangkaian BJT dengan beban resistor $20 \Omega$

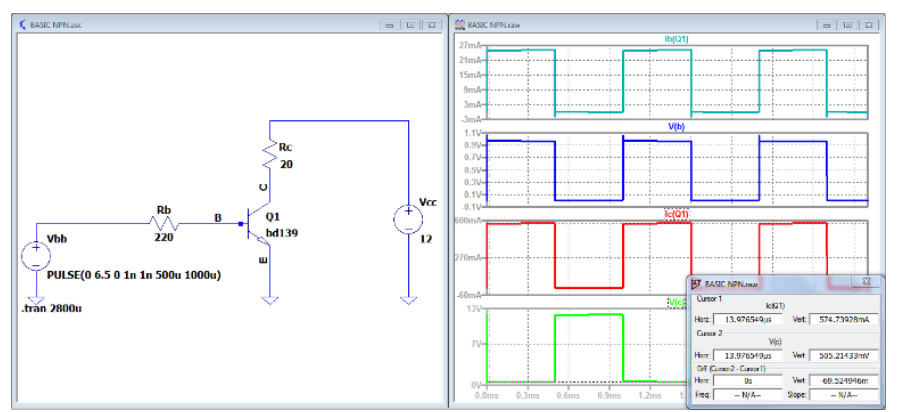

(a)

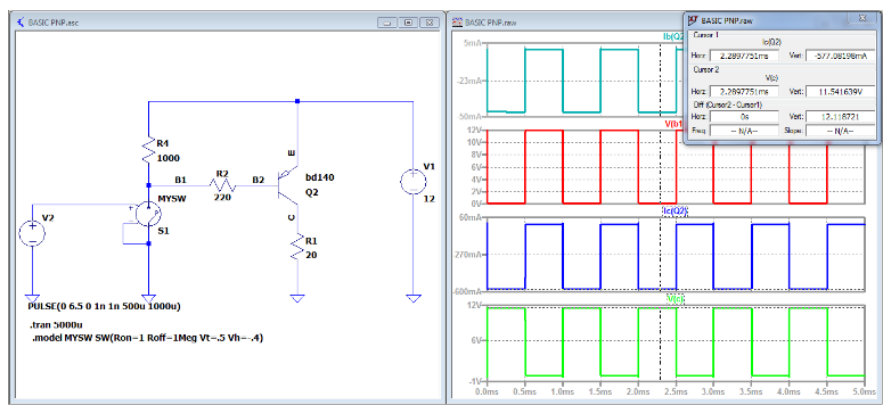

(b)

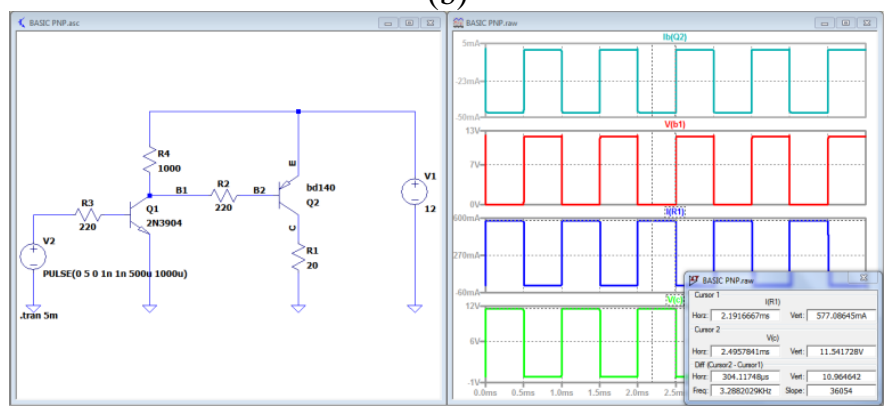

(c)

Gambar 7. Simulasi LTspice pada beban resistor $20 \Omega$, (a) Rangkaian BJT NPN BD139, (b) Rangkaian BJT PNP BD140 dengan sakelar, (c) Rangkaian PNP BJT BD140 dengan BJT NPN

Submitted: 20/10/2019 Revised: 24/11/2019;

Accepted: 24/11/2019; Online first: 30/06/2020

http://dx.doi.org/10.46964/poligrid.v1i1.343 
Dengan menggunakan simulasi LTspice terlihat bahwa dengan menggunakan resistor $220 \Omega$ pada basis BJT BD139 dapat mencapai saturation dengan tegangan collector emitter $\mathrm{V}_{\mathrm{CE}}$ yaitu $0,505 \mathrm{~V}$ dan arus collector yaitu sebesar 0,574 A sedangkan BJT BD140 pada Gambar 7 (b) menggunakan sakelar dan pada Gambar 7 (c) menggunakan BJT NPN 2N3904 sebagai sakelar pada basis karena kondisi pengaktifan BJT PNP kondisi basis harus dalam keadaan low (terhubung dengan ground), serta tegangan pada beban adalah sebesar 11,54 $\mathrm{V}$ dan arus collector yaitu sebesar $0,577 \mathrm{~A}$.

2). Rangkaian BJT dengan beban resistor $100 \Omega$ dan induktor $58 \mathrm{mH}$

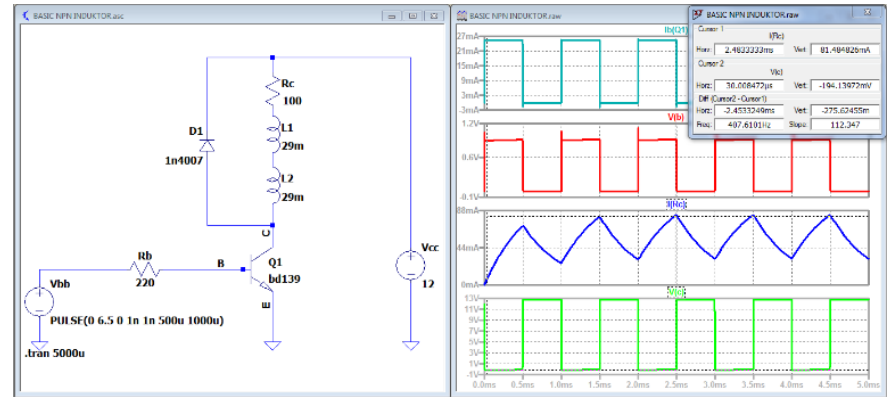

(a)

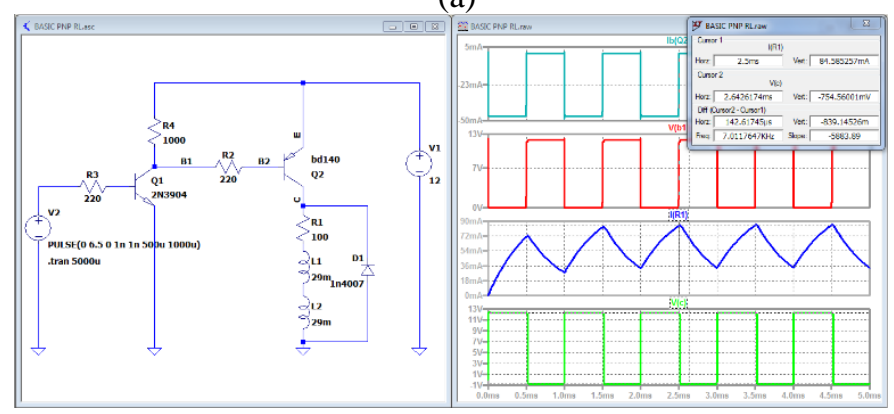

(b)

Gambar 8. Simulasi LTspice pada beban resistor dan induktor, (a) Rangkaian BJT NPN BD139, (b) Rangkaian PNP BJT BD140

Untuk rangkaian dengan beban resistor dan induktor, resistor yang digunakan adalah $100 \Omega$ dan dua induktor dengan nilai masing-masing $29 \mathrm{mH}$ yang dihubungkan secara seri. Dari hasil simulasi pada frekuensi $1 \mathrm{KHz}$ dan duty cycle $50 \%$, arus collector tidak dapat turun ke nilai minimum saat BJT kondisi cut off dikarenakan sifat induktansi dari induktor yaitu menyimpan energi listrik dalam bentuk medan magnet dan melawan perubahan arus.

Setelah melakukan perhitungan manual maupun simulasi dengan LTspice rangkaian di uji coba pada breadboard, perancangan rangkaian dlakukan dengan menggunakan aplikasi Fritzing. Untuk sumber sinyal PWM digunakan pin 11 pada Arduino Mega. Gambar rangkaian breadboard dapat dilihat pada Gambar 9.

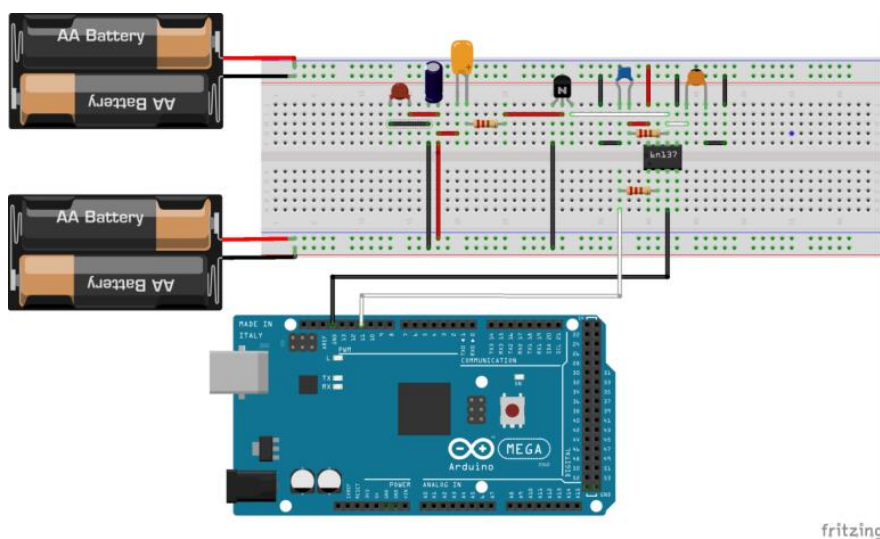

(a)

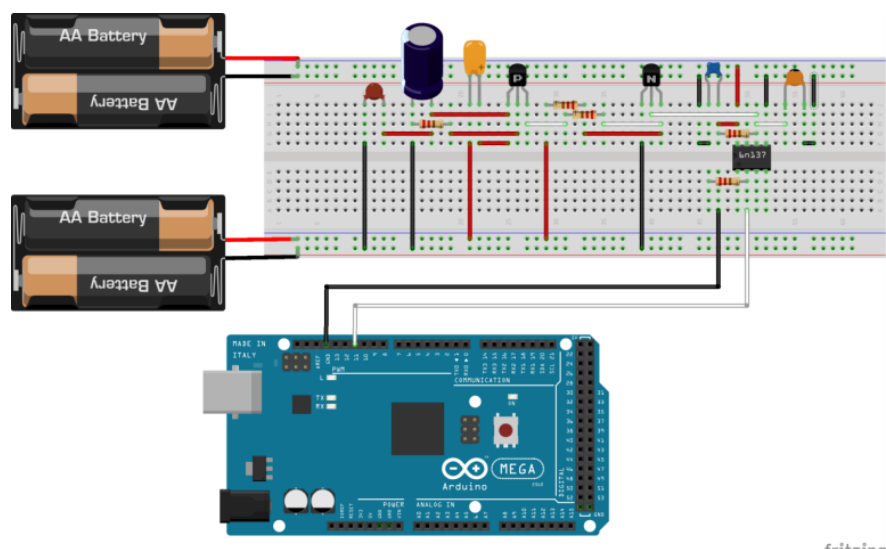

(b)

Gambar 9. Perancangan Rangkaian BJT pada Breadboard, (a) Rangkaian BJT NPN BD139, (b) Rangkaian BJT PNP BD140

Setelah melakukan perancangan manual, simulasi, maupun pada breadboard. Selanjutnya melakukan perancangan jalur PCB pada aplikasi Autodesk Eagle.

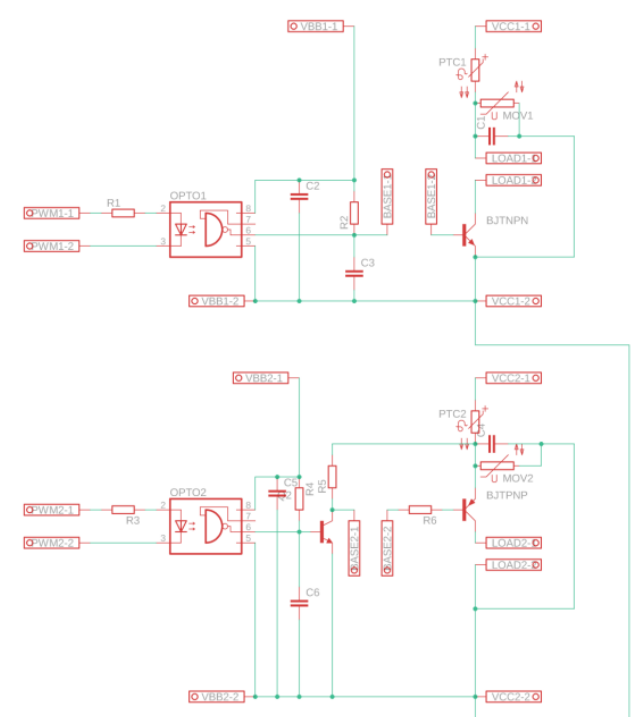

(a)

Submitted: 20/10/2019 Revised: 24/11/2019;

Accepted: 24/11/2019; Online first: 30/06/2020

http://dx.doi.org/10.46964/poligrid.v1i1.343 


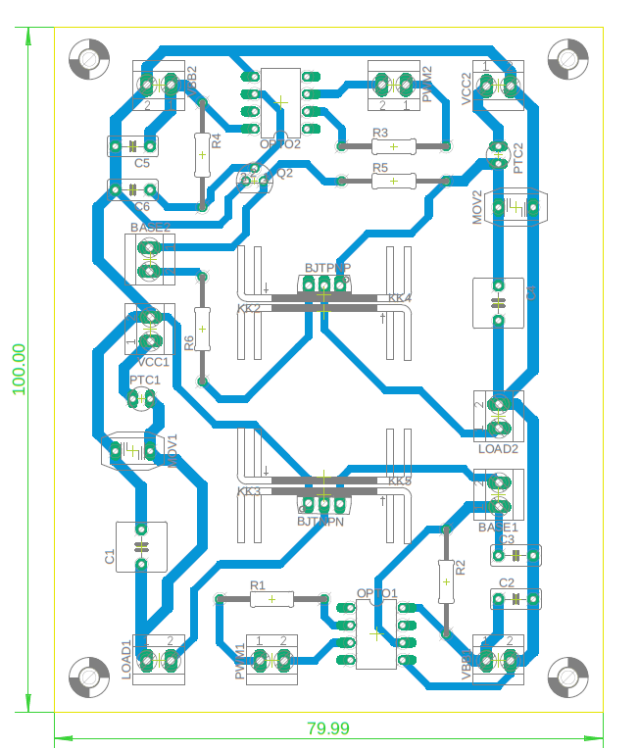

(b)

Gambar 10. Rangkaian BJT NPN dan BJT PNP, (a) Gambar schematic rangkaian, (b) Gambar rangkaian jalur PCB

\section{Perancangan pengaturan pengendali PWM}

Perancangan pengaturan pengendali PWM dibuat dengan aplikasi Fritzing. Pengendali PWM menggunakan rotary encoder sebagai input pada Arduino Mega 2560 yang ditampilkan pada LCD I2C. Berikut adalah gambar rangkaian yang dapat dilihat pada Gambar 11.

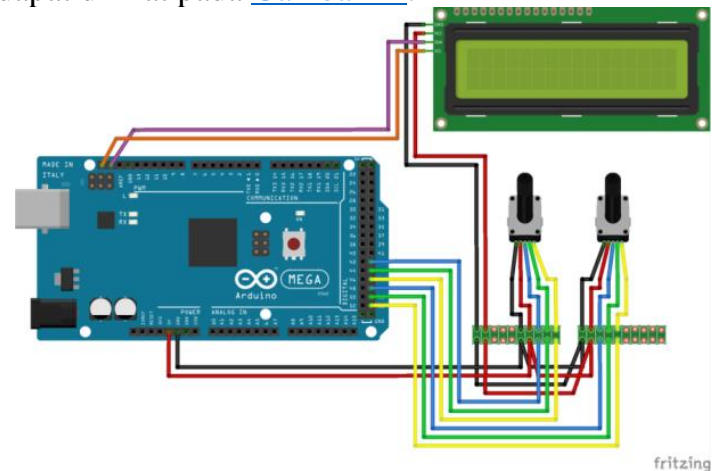

Gambar 11. Perancangan pengaturan pengendali PWM

\section{E. Perancangan Multiplexer}

Papan multiplexer digunakan sebagai sakelar pemilih untuk mengaktifkan rangkaian sakelar yang akan digunakan. Dalam tegangan BJT jenis multiplexer yang digunakan adalah 74HC4067 yang merupakan multiplexer dengan 16 channel analog. terdapat dua channel yang digunakan sebagai output PWM, yaitu channel 11 untuk BJT NPN dan channel 12 untuk BJT PNP. Berikut adalah gambar dari perancangan rangkaian multiplexer yang ditunjukkan pada Gambar 12.

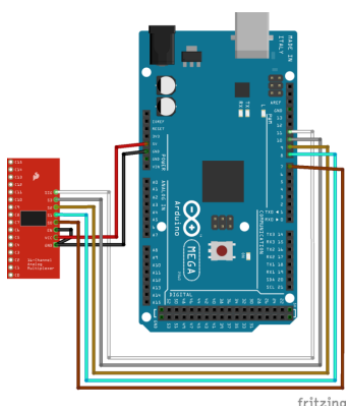

Gambar 12. Perancangan multiplexer

\section{F. Perancangan Box atau Wadah Modul Praktikum}

Perancangan box atau wadah dilakukan dibuat pada aplikasi Autodesk Fusion 360. Box atau wadah digunakan sebagai tempat untuk menempatkan seluruh komponen, box berbahan akrilik tembus pandang agar rangkaian sistem didalamnya dapat terlihat dengan jelas. Berikut adalah gambar desain box atau wadah yang dapat dilihat pada Gambar 13 .

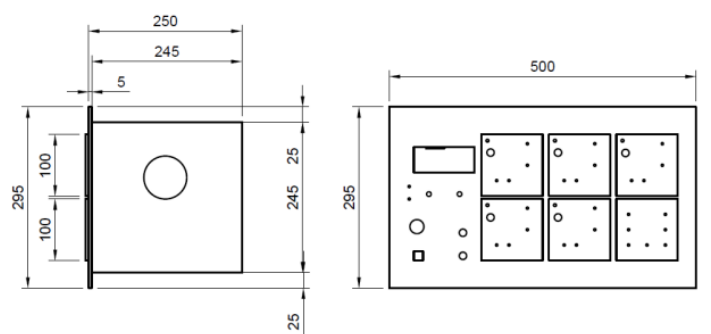

(a)

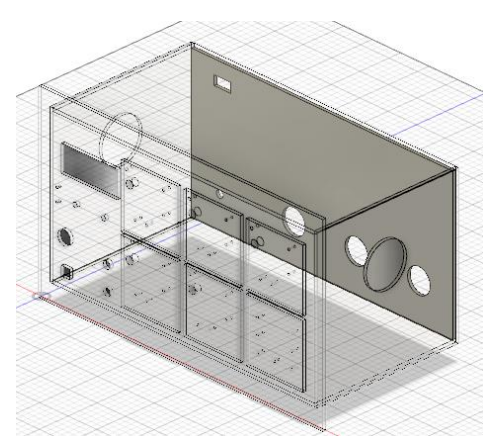

(b)

Gambar 13. Perancangan box atau wadah modul praktikum, (a) Dimensi box atau wadah, (b) Desain 3D box atau wadah

\section{G. Diagram Alir}

Pada modul praktikum penggunaan BJT sebagai sakelar terdapat diagram alir pemrograman yang dibuat berdasarkan sketch atau program pada Arduino IDE. Berikut adalah diagram alir yang dapat dilihat pada Gambar 14 . 


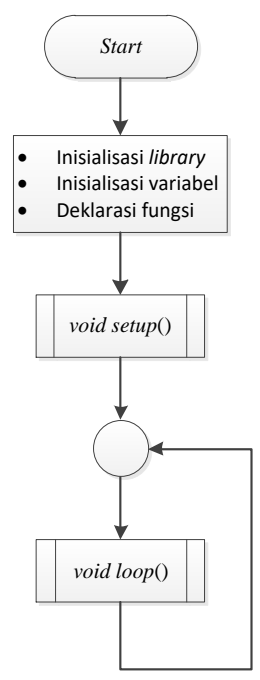

(a)

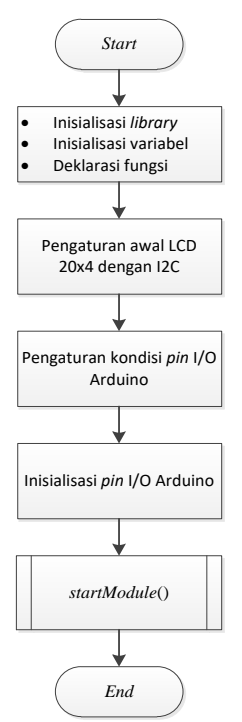

(b)

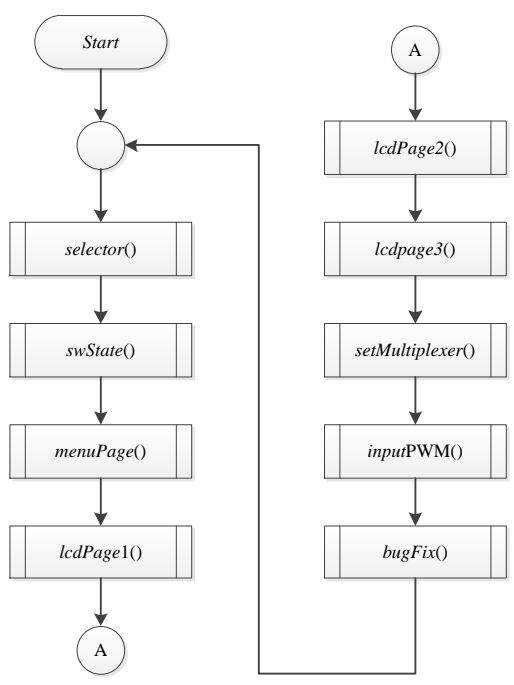

(c)

Gambar 14. Diagram alir pemrograman Arduino, (a) Diagram utama, (b) Diagram alir void setup(), (c) Diagram alir void loop()

Submitted: 20/10/2019 Revised: 24/11/2019;

Accepted: 24/11/2019; Online first: 30/06/2020

http://dx.doi.org/10.46964/poligrid.v1i1.343

\section{IV.HASIL DAN PEMBAHASAN}

\section{A. Pengujian BJT dengan Percobaan 1}

Percobaan 1 merupakan pergujian BJT NPN dengan beban berupa resistor $20 \Omega$ dengan nilai frekuensi dan duty cycle yang divariasikan sesuai dengan tabel percobaan. Berikut merupakan hasil pengujian yang ditunjukkan pada Gambar 15 .

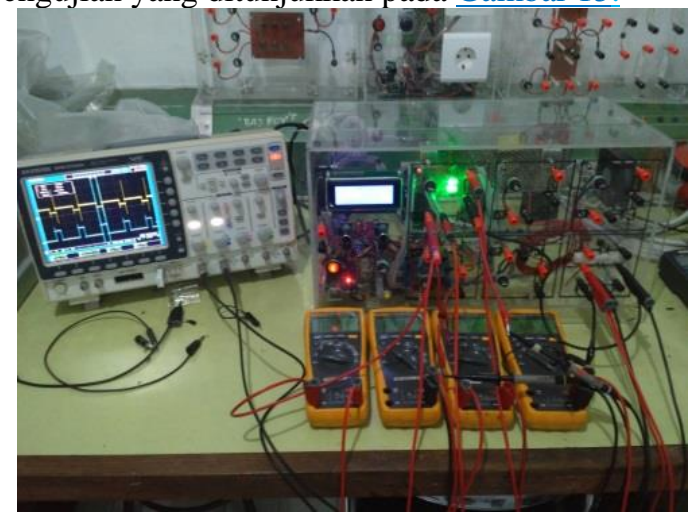

(a)

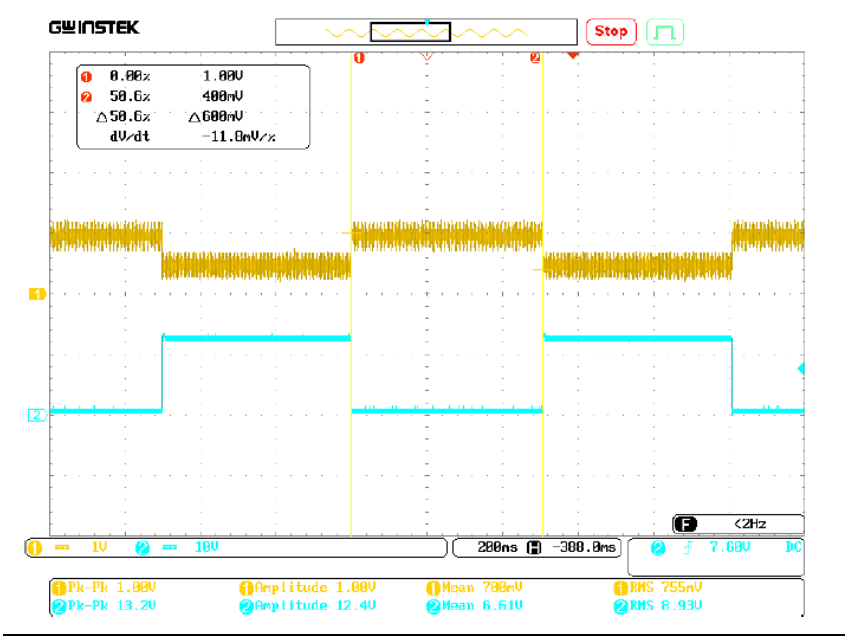

$\underline{(b)}$

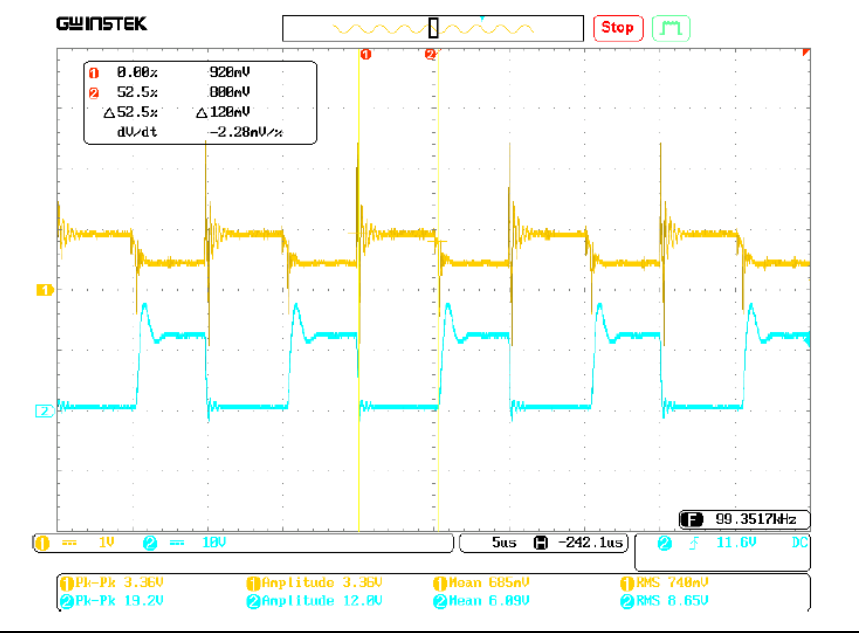

(c)

Gambar 15. Pengujian BJT NPN dengan percobaan 1 DTC 50\%, (a) Gambar rangkaian, (b) frekuensi $1 \mathrm{~Hz}$, (c) frekuensi $100 \mathrm{KHz}$ 
TABEL 2

PENGUJIAN BJT DENGAN PERCOBAAN 1 PADA FREKUENSI RENDAH

\begin{tabular}{|c|c|c|c|c|c|}
\hline \multirow{2}{*}{$\begin{array}{l}\text { Freq } \\
(\mathbf{H z})\end{array}$} & \multirow{2}{*}{$\begin{array}{l}\text { DTC } \\
(\%)\end{array}$} & \multicolumn{2}{|l|}{ Beban } & \multicolumn{2}{|l|}{ Base } \\
\hline & & $\begin{array}{c}\text { Tegangan } \\
\text { (V) }\end{array}$ & $\begin{array}{c}\text { Arus } \\
\text { (A) }\end{array}$ & $\begin{array}{c}\text { Tegangan } \\
\text { (V) }\end{array}$ & $\begin{array}{c}\text { Arus } \\
\text { (A) }\end{array}$ \\
\hline \multirow[t]{3}{*}{1} & 0 & 0 & 0,003 & 0,417 & 0,002 \\
\hline & 50 & 5,79 & 0,288 & 0,700 & 0,011 \\
\hline & 100 & 11,44 & 0,572 & 0,917 & 0,028 \\
\hline \multirow[t]{3}{*}{50} & 0 & 0 & 0,003 & 0,417 & 0,002 \\
\hline & 50 & 5,706 & 0,282 & 0,665 & 0,016 \\
\hline & 100 & 11,44 & 0,571 & 0,917 & 0,028 \\
\hline \multirow[t]{3}{*}{100} & 0 & 0 & 0,003 & 0,417 & 0,002 \\
\hline & 50 & 5,743 & 0,285 & 0,665 & 0,016 \\
\hline & 100 & 11,45 & 0,571 & 0,917 & 0,028 \\
\hline
\end{tabular}

TABEL 3

PENGUJIAN BJT DENGAN PERCOBAAN 1 PADA FREKUENSI TINGGI

\begin{tabular}{|c|c|c|c|c|c|}
\hline \multirow{2}{*}{$\begin{array}{l}\text { Freq } \\
(\mathbf{K H z})\end{array}$} & \multirow{2}{*}{$\begin{array}{l}\text { DTC } \\
(\%)\end{array}$} & \multicolumn{2}{|l|}{ Beban } & \multicolumn{2}{|l|}{ Base } \\
\hline & & $\begin{array}{l}\text { Tegangan } \\
\text { (V) }\end{array}$ & $\begin{array}{l}\text { Arus } \\
\text { (A) }\end{array}$ & $\begin{array}{l}\text { Tegangan } \\
\text { (V) }\end{array}$ & $\begin{array}{c}\text { Arus } \\
\text { (A) }\end{array}$ \\
\hline \multirow[t]{3}{*}{1} & 0 & 0 & 0,003 & 0,417 & 0,002 \\
\hline & 50 & 5,806 & 0,288 & 0,664 & 0,016 \\
\hline & 100 & 11,45 & 0,572 & 0,917 & 0,028 \\
\hline \multirow[t]{3}{*}{50} & 0 & 0 & 0,003 & 0,417 & 0,002 \\
\hline & 50 & 6,007 & 0,298 & 0,669 & 0,015 \\
\hline & 100 & 11,45 & 0,572 & 0,918 & 0,028 \\
\hline \multirow[t]{3}{*}{100} & 0 & 0 & 0,003 & 0,417 & 0,002 \\
\hline & 50 & 6,201 & 0,307 & 0,675 & 0,016 \\
\hline & 100 & 11,45 & 0,572 & 0,918 & 0,028 \\
\hline
\end{tabular}

Dari hasil pengujian yang dilakukan, kanal 1 (kuning) merupakan gelombang pada basis dan kanal 2 (biru) merupakan tegangan kolektor emiter. Saat diberikan frekuensi $1 \mathrm{~Hz}$ gelombang terlihat bagus dan sesuai antara basis dan kolektor emitter sedangkan saat frekuensi dinaikkan ke $100 \mathrm{KHz}$ gelombang terlihat tidak bagus antara gelombang basis dan kolektor emiter terjadi selisih dan terdapat ringing pada gelombang.

\section{B. Pengujian BJT dengan Percobaan 2}

Percobaan 2 merupakan pergujian BJT NPN dengan beban berupa resistor $100 \Omega$ dan induktor $58 \mathrm{mH}$ dengan nilai frekuensi dan duty cycle yang divariasikan sesuai dengan tabel percobaan. Berikut merupakan hasil pengujian yang ditunjukkan pada Gambar 16.

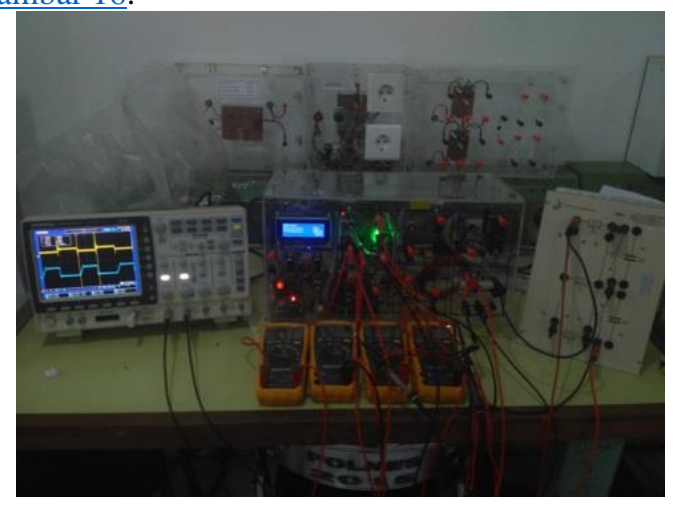

(a)

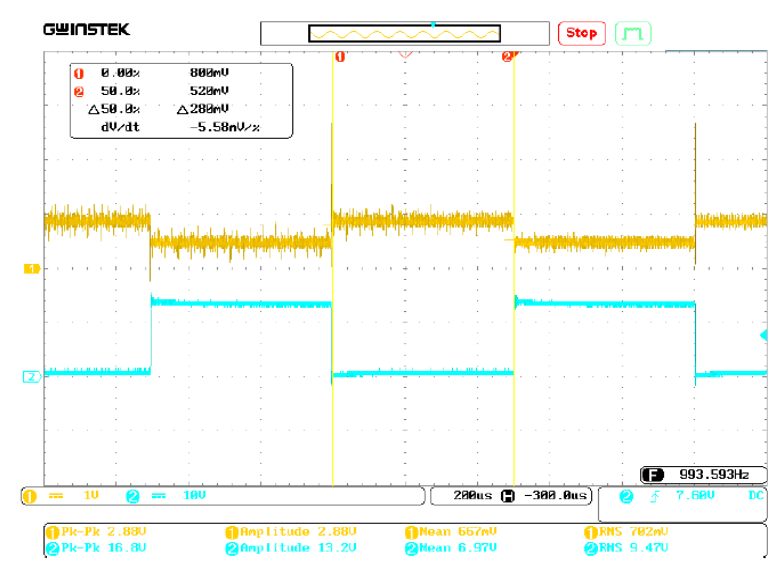

(b)

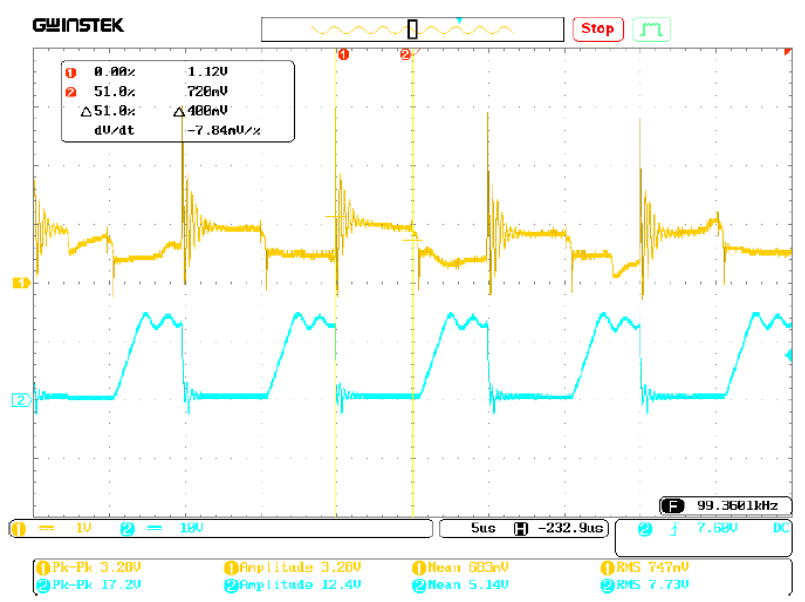

(c)

Gambar 16. Pengujian BJT NPN dengan percobaan 2 DTC 50\%, (a) Gambar rangkaian, (b) frekuensi $1 \mathrm{KHz}$, (c) frekuensi $100 \mathrm{KHz}$

TABEL 4

PENGUJIAN BJT DENGAN PERCOBAAN 2

\begin{tabular}{|c|c|c|c|c|c|}
\hline \multirow{2}{*}{$\begin{array}{l}\text { Freq } \\
\text { (KHz) }\end{array}$} & \multirow{2}{*}{$\begin{array}{l}\text { DTC } \\
(\%)\end{array}$} & \multicolumn{2}{|l|}{ Beban } & \multicolumn{2}{|l|}{ Base } \\
\hline & & $\begin{array}{c}\text { Tegangan } \\
\text { (V) }\end{array}$ & $\begin{array}{l}\text { Arus } \\
\text { (A) }\end{array}$ & $\begin{array}{c}\text { Tegangan } \\
\text { (V) }\end{array}$ & $\begin{array}{c}\text { Arus } \\
\text { (A) }\end{array}$ \\
\hline \multirow[t]{3}{*}{1} & 0 & 0 & 0,003 & 0,417 & 0,002 \\
\hline & 50 & 5,664 & 0,032 & 0,621 & 0,016 \\
\hline & 100 & 11,81 & 0,122 & 0,838 & 0,028 \\
\hline \multirow[t]{3}{*}{50} & 0 & 0 & 0,003 & 0,417 & 0,002 \\
\hline & 50 & 6,68 & 0,061 & 0,636 & 0,016 \\
\hline & 100 & 11,81 & 0,122 & 0,839 & 0,028 \\
\hline \multirow[t]{3}{*}{100} & 0 & 0 & 0,003 & 0,417 & 0,002 \\
\hline & 50 & 7,33 & 0,071 & 0,639 & 0,016 \\
\hline & 100 & 11,81 & 0,122 & 0,839 & 0,028 \\
\hline
\end{tabular}

Dari hasil pengujian yang dilakukan, kanal 1 (kuning) merupakan gelombang pada basis dan kanal 2 (biru) merupakan tegangan kolektor emiter. Saat diberikan frekuensi $1 \mathrm{KHz}$ gelombang terlihat bagus dan sesuai antara basis dan kolektor emitter sedangkan saat frekuensi dinaikkan ke $100 \mathrm{KHz}$ gelombang terlihat tidak bagus antara gelombang basis dan kolektor emiter terjadi selisih dan terdapat ringing pada gelombang.

Submitted: 20/10/2019 Revised: 24/11/2019;

Accepted: 24/11/2019; Online first: 30/06/2020

http://dx.doi.org/10.46964/poligrid.v1i1.343 


\section{Pengujian BJT dengan Percobaan 3}

Percobaan 3 merupakan pergujian BJT PNP dengan beban berupa resistor $20 \Omega$ dengan nilai frekuensi dan duty cycle yang divariasikan sesuai dengan tabel percobaan. Berikut merupakan hasil pengujian yang ditunjukkan pada Gambar 17.

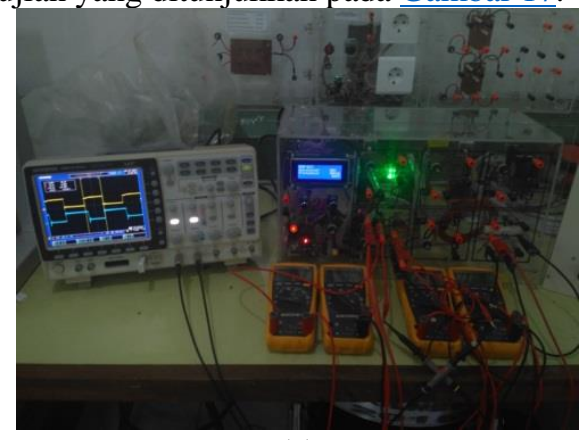

(a)

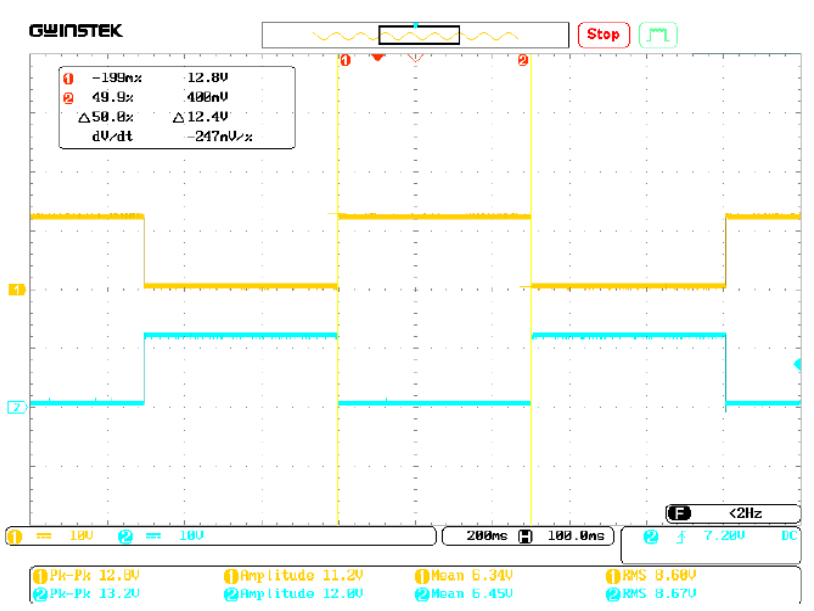

(b)

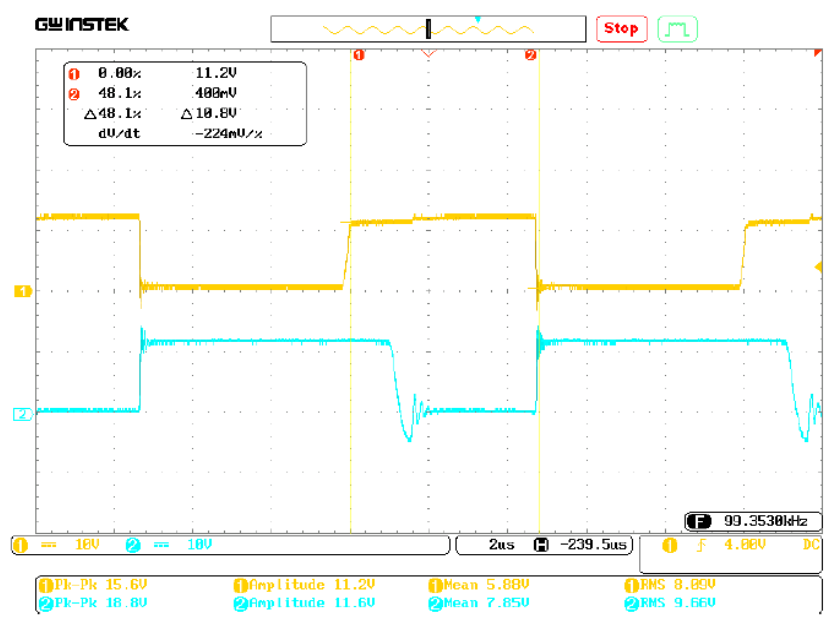

(c)

Gambar 17. Pengujian BJT PNP dengan percobaan 3 DTC 50\%, (a) Gambar rangkaian, (b) frekuensi $1 \mathrm{~Hz}$, (c) frekuensi $100 \mathrm{KHz}$
TABEL 5

PENGUJIAN BJT DENGAN PERCOBAAN 3 PADA FREKUENSI RENDAH

\begin{tabular}{|c|c|c|c|c|c|}
\hline \multirow{2}{*}{$\begin{array}{l}\text { Freq } \\
(\mathbf{H z})\end{array}$} & \multirow{2}{*}{$\begin{array}{l}\text { DTC } \\
(\%)\end{array}$} & \multicolumn{2}{|l|}{ Beban } & \multicolumn{2}{|l|}{ Base } \\
\hline & & $\begin{array}{c}\text { Tegangan } \\
\text { (V) }\end{array}$ & $\begin{array}{c}\text { Arus } \\
\text { (A) }\end{array}$ & $\begin{array}{c}\text { Tegangan } \\
\text { (V) }\end{array}$ & $\begin{array}{l}\text { Arus } \\
\text { (A) }\end{array}$ \\
\hline \multirow[t]{3}{*}{1} & 0 & 11,45 & 0,573 & 0,069 & 0,052 \\
\hline & 50 & 6,45 & 0,323 & 6,34 & 0,025 \\
\hline & 100 & 11,44 & 0,572 & 0,917 & 0,028 \\
\hline \multirow[t]{3}{*}{50} & 0 & 0 & 0,003 & 0,417 & 0,002 \\
\hline & 50 & 5,70 & 0,282 & 6,076 & 0,028 \\
\hline & 100 & 0 & 0,003 & 11,93 & 0,002 \\
\hline \multirow[t]{3}{*}{100} & 0 & 11,44 & 0,571 & 0,002 & 0,052 \\
\hline & 50 & 5,75 & 0,285 & 6,025 & 0,028 \\
\hline & 100 & 0 & 0,003 & 11,94 & 0,002 \\
\hline
\end{tabular}

TABEL 6

PENGUJIAN BJT DENGAN PERCOBAAN 3 PADA FREKUENSI TINGGI

\begin{tabular}{|c|c|c|c|c|c|}
\hline \multirow{2}{*}{$\begin{array}{l}\text { Freq } \\
\text { (KHz) }\end{array}$} & \multirow{2}{*}{$\begin{array}{l}\text { DTC } \\
(\%)\end{array}$} & \multicolumn{2}{|l|}{ Beban } & \multicolumn{2}{|l|}{ Base } \\
\hline & & $\begin{array}{c}\text { Tegangan } \\
\text { (V) }\end{array}$ & $\begin{array}{c}\text { Arus } \\
\text { (A) }\end{array}$ & $\begin{array}{c}\text { Tegangan } \\
\text { (V) }\end{array}$ & $\begin{array}{c}\text { Arus } \\
\text { (A) }\end{array}$ \\
\hline \multirow[t]{3}{*}{1} & 0 & 11,44 & 0,571 & 0,069 & 0,052 \\
\hline & 50 & 5,82 & 0,289 & 5,961 & 0,027 \\
\hline & 100 & 0 & 0,003 & 11,93 & 0,002 \\
\hline \multirow[t]{3}{*}{50} & 0 & 11,44 & 0,571 & 0,069 & 0,052 \\
\hline & 50 & 6,64 & 0,331 & 5,66 & 0,028 \\
\hline & 100 & 0 & 0,003 & 11,93 & 0,002 \\
\hline \multirow[t]{3}{*}{100} & 0 & 11,44 & 0,571 & 0,069 & 0,052 \\
\hline & 50 & 7,37 & 0,365 & 5,510 & 0,028 \\
\hline & 100 & 0 & 0,003 & 11,93 & 0,002 \\
\hline
\end{tabular}

Dari hasil pengujian yang dilakukan, kanal 1 (kuning) merupakan gelombang pada basis dan kanal 2 (biru) merupakan tegangan beban. Saat diberikan frekuensi $1 \mathrm{~Hz}$ gelombang terlihat bagus dan sesuai antara basis dan beban sedangkan saat frekuensi dinaikkan ke $100 \mathrm{KHz}$ gelombang terlihat tidak bagus antara gelombang basis dan beban terjadi selisih dan terdapat ringing pada gelombang.

\section{Pengujian BJT dengan Percobaan 4}

Percobaan 4 merupakan pergujian BJT NPN dengan beban berupa resistor $100 \Omega$ dan induktor $58 \mathrm{mH}$ dengan nilai frekuensi dan duty cycle yang divariasikan sesuai dengan tabel percobaan. Berikut merupakan hasil pengujian yang ditunjukkan pada Gambar 18.

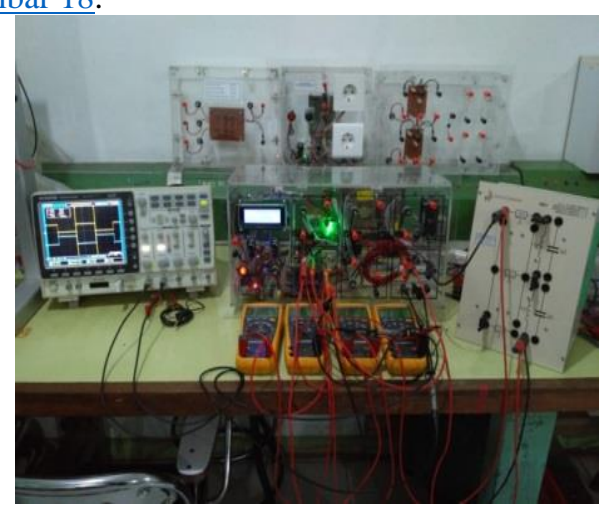

(a) 


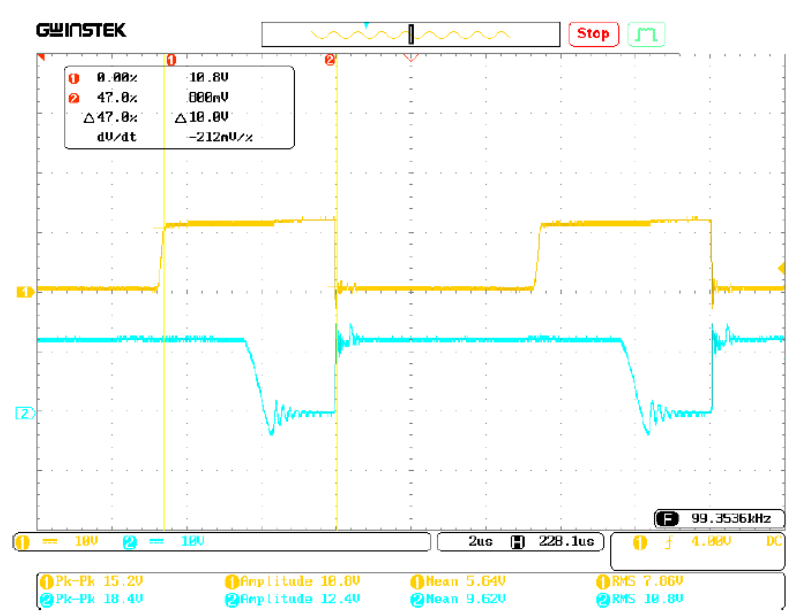

(b)

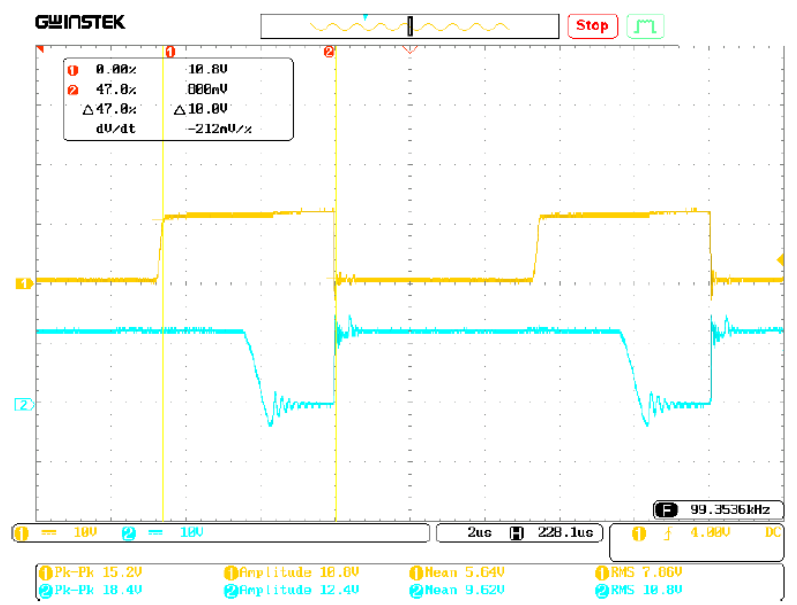

(c)

Gambar 18. Pengujian BJT PNP dengan percobaan 2 DTC 50\%, (a) Gambar rangkaian, (b) frekuensi $1 \mathrm{KHz}$, (c) frekuensi $100 \mathrm{KHz}$

TABEL 7

PENGUJIAN BJT DENGAN PERCOBAAN 4

\begin{tabular}{|l|l|l|l|l|c|}
\hline \multirow{2}{*}{$\begin{array}{l}\text { Freq } \\
(\text { KHz })\end{array}$} & \multirow{2}{*}{$\begin{array}{l}\text { DTC } \\
(\%)\end{array}$} & \multicolumn{2}{|l|}{ Beban } & \multicolumn{2}{l|}{ Base } \\
\cline { 3 - 6 } & & $\begin{array}{c}\text { Tegangan } \\
(\mathbf{V})\end{array}$ & $\begin{array}{c}\text { Arus } \\
(\mathbf{A})\end{array}$ & $\begin{array}{c}\text { Tegangan } \\
(\mathbf{V})\end{array}$ & $\begin{array}{c}\text { Arus } \\
(\mathbf{A})\end{array}$ \\
\hline \multirow{3}{*}{1} & 0 & 11,79 & 0,121 & 0,064 & 0,053 \\
\cline { 2 - 6 } & 50 & 5,67 & 0,034 & 5,979 & 0,028 \\
\cline { 2 - 6 } & 100 & 0 & 0,003 & 11,94 & 0,002 \\
\hline 50 & 0 & 11,79 & 0,122 & 0,064 & 0,053 \\
\cline { 2 - 6 } & 50 & 7,44 & 0,275 & 5,67 & 0,028 \\
\cline { 2 - 6 } & 100 & 0 & 0,003 & 11,94 & 0,002 \\
\hline \multirow{3}{*}{100} & 0 & 11,79 & 0,121 & 0,064 & 0,053 \\
\cline { 2 - 6 } & 50 & 9,15 & 0,090 & 5,346 & 0,029 \\
\cline { 2 - 6 } & 100 & 0 & 0,003 & 11,94 & 0,002 \\
\hline
\end{tabular}

Dari hasil pengujian yang dilakukan, kanal 1 (kuning) merupakan gelombang pada basis dan kanal 2 (biru) merupakan tegangan beban. Saat diberikan frekuensi $1 \mathrm{KHz}$ gelombang terlihat bagus dan sesuai antara basis dan beban sedangkan saat frekuensi dinaikkan ke $100 \mathrm{KHz}$ gelombang terlihat tidak bagus antara gelombang basis dan beban terjadi selisih dan terdapat ringing pada gelombang.

\section{E. Konsumsi daya}

Modul praktikum yang telah dibuat memiliki konsumsi daya PLN yang terbagi pada pengukuran tanpa beban atau beban 0 , pengukuran beban $\mathrm{R}$ dan pengukuran beban RL yang dapat dilihat pada Gambar 19 dan Tabel 8.

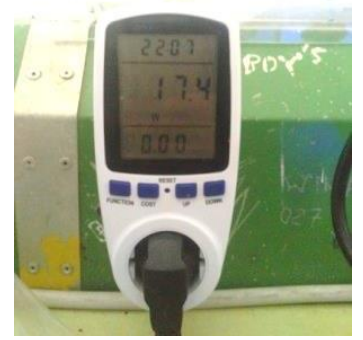

(a)

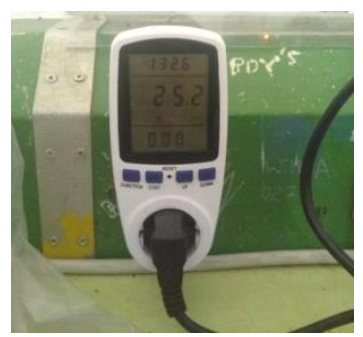

(b)

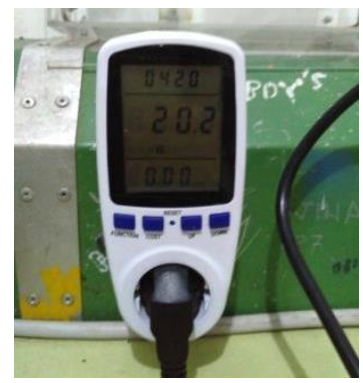

(c)

Gambar 19. Konsumsi daya PLN pada modul praktikum, (a) tanpa beban, (b) beban resistor, (c) beban resistor dan induktor

TABEL 8

KONSUMSI DAYA PLN PADA MODUL PRAKTIKUM

\begin{tabular}{|c|c|c|c|}
\hline Beban & Tegangan (V) & Arus (A) & Daya (W) \\
\hline 0 & 231,6 & 0,136 & 17,4 \\
\hline R & 232,4 & 0,194 & 25,2 \\
\hline RL & 234,5 & 0,161 & 20,2 \\
\hline
\end{tabular}

\section{KESIMPULAN DAN SARAN}

\section{A. Kesimpulan}

Kesimpulan yang didapatkan Berdasarkan hasil pengujian yaitu, saat cut off untuk BJT NPN dan BJT PNP pada beban resistor maupun resistor dengan induktor, nilai tegangan beban $0 \mathrm{~V}$ dan arus beban 0,003 A. sedangkan saat saturation pada beban resistor untuk BJT NPN, nilai tegangan beban $11,45 \mathrm{~V}$ dan arus beban 0,572 A dan BJT PNP, nilai tegangan beban $11,45 \mathrm{~V}$ dan arus beban 0,573 A. pada beban resistor dengan induktor untuk BJT NPN, nilai tegangan beban $11,81 \mathrm{~V}$ dan arus

Submitted: 20/10/2019 Revised: 24/11/2019;

Accepted: 24/11/2019; Online first: 30/06/2020

http://dx.doi.org/10.46964/poligrid.v1i1.343 
beban 0,122 A dan BJT PNP, nilai tegangan beban 11,79 V dan arus beban $0,121 \mathrm{~A}$. serta konsumsi daya PLN pada saat tanpa beban adalah $17,4 \mathrm{~W}$, saat dibebani resistor adalah $25,2 \mathrm{~W}$, dan saat dibebani resistor dengan induktor adalah 20,2 W.

\section{B. Saran}

Penyempurnaan pada modul praktikum Penggunaan Bipolar Junction Transistor Sebagai Sakelar Berbasis Arduino Mega dapat dilakukan penambahan IR Remote sebagai pengontrol PWM untuk pengaturan nilai duty cyle dan frekuensi serta penambahan untuk variasi beban dengan menggunakan motor PMDC (Permanent Magnet Direct Current) dengan rating tegangan $12 \mathrm{~V}$.

\section{REFERENSI}

[1] Panduan Penyusunan Kurikulum Pendidikan Vokasi $1^{\text {st }}$ ed., Ristekdikti Jakarta, 2016.

[2] Panduan Teknologi Pembelajaran Vokasi $1^{\text {st }}$ ed., Ristekdikti, Jakarta, 2016.

[3] "BD139 datasheet," NPN Power Transistors, Phillips Semiconductor, Mar. 1997.

[4] “BD140 datasheet," PNP Power Transistors, Phillips Semiconductor, Mar. 1997.

[5] Elprocus, How to Use Transistors As A Switch. Accessed January 22, 2019, [Online] Available https://www.elprocus.com/using-transistor-asa-switch/

[6] T. L. Floyd, Electronic Devices $9^{\text {th }}$ ed, New Jersey, 2012. [E-book].

[7] A. Malvino and D. Bates, Electronic Principles, Edition 8, McGraw-Hill Education,2011. [E-book].

[8] Sparkfun, Transistors, Accessed July, 2019, [Online] Available https://learn.sparkfun.com/tutorials/transistors/applications-i-switches

[9] Abdul Kadir, Simulasi Arduino, PT Elex Media Komputindo, Jakarta, 2016.

[10] Arduino, Arduino Introduction, Accessed January 22, 2019, [Online] Available https://www.arduino.cc/en/guide/introduction

[11] Arduino, Arduino Mega 2560 Rev 3. Accessed June, 2019, [Online] Available https://store.arduino.cc/usa/arduino-mega-adk-rev3.

[12] Arduino, PWM, Accessed June, 2019 .[Online] Available https://www.arduino.cc/en/tutorial/PWM. 